\title{
Um fio de diferença: masculinidades no mundo do trabalho, 1870-1910*
}

Gil Mihaely**

Resumo. Na paisagem social francesa do século XIX, quando a classe operária se definiu contra um papel de dependência, pelo menos entre os operários organizados, a domesticidade masculina desempenha um papel estruturante na cristalização de suas identidades. O doméstico é o modelo por excelência de uma posição de dependência, e em torno dele se articulam representações sociais fundamentais. A análise de dois conflitos sociais protagonizados, entre os anos de 1870 e os anos de 1910, pelos garçons de café e pelos agentes ambulantes do Banco da França pelo direito de usar bigodes desvenda os mecanismos sociais e culturais desse fenômeno. Ela demonstra como o valor masculino - ou feminino - de algumas posições no mundo do trabalho pesa na construção de identidades e de pertencimentos. Os operários se encontram em um campo identitário em que os domésticos formam o pólo feminino, e os militares - enquanto representação de uma masculinidade hegemônica - o pólo viril. Assim, como ilustram os dois casos estudados, eles se posicionam definindo-se em relação a esses dois pivôs identitários e travam uma luta não somente contra seus patrões, mas também contra a clientela e mesmo

* Tradução de Germano Weirich, bacharelado francês/português UFRGS. Revisão técnica de Temístocles Cezar e Benito Schmidt (ambos do PPG em História da UFRGS).

** Doutor em História pela École des Hautes Études en Sciences Sociales (EHESS), pesquisador do centro Approches Historiques des Mondes Contemporains (EHESS) e jornalista.

Anos 90, Porto Alegre, v. 14, n. 25, p.17-35, jul. 2007 
Um fio de diferença: masculinidades no mundo do trabalho, 1870-1910

contra alguns de seus "colegas" cujo status dependia da existência de uma categoria inferior de operários.

Palavras-chave: Domésticos. Empregados domésticos. Garçons de receitas. Garçons de café. Garçons de bares. Restaurantes. Cafés. Virilidade. Masculinidade. Operários. Identidade. Bigode. Banco da França.

A cristalização de identidades sociais é um fenômeno complexo que ultrapassa, evidentemente, a ambição desta pequena demonstração. Esta se contentará em evidenciar o papel estruturante da domesticidade masculina na paisagem social do século XIX através do estudo de dois conflitos sociais protagonizados, entre os anos de 1870 e os anos de 1910, pelos garçons de cafés e os agentes externos do Banco da França pelo direito de usar bigodes. Como destacou Christophe Charles, "a própria noção de classe operária definiu-se, entre os operários organizados, contra a imposição desse papel de dependência que algumas formas de paternalismo procuram instaurar ou restaurar".' O empregado doméstico é o modelo por excelência desse "papel de dependência", em torno do qual se articulam representações sociais fundamentais. Tentaremos salientar a maneira como o valor masculino - ou feminino - de algumas posições no mundo do trabalho pesa na construção de identidades e de pertencimentos: os empregados domésticos formam o pólo feminino, e os militares - enquanto representação de uma masculinidade hegemônica -, o pólo viril. Outros grupos se posicionam definindo-se em relação a esses dois pivôs, como ilustra o exemplo de dois grupos de trabalhadores em ramos de serviços, os garçons de receitas ${ }^{2}$ do Banco da França e os garçons de restaurantes, em uma época que abrange a "primeira" Terceira República. ${ }^{3}$

A domesticidade, instituição social herdada do "Antigo Regime", ocupa no século XIX um lugar decisivo na formação de novos imaginários e novas identidades. Ela representa as antigas relações de produção condenadas à decadência, e "o doméstico", enquanto representação social, sofre as conseqüências disso.

Anos 90, Porto Alegre, v. 14, n. 25, p.17-35, jul. 2007 
Quais são os elementos-chave desse imaginário? As noções de independência e de produtividade parecem ser os fundamentos da respeitabilidade e da identidade sócio-profissional dos operários. Ser patrão, ou pelo menos ser dono de seu próprio nariz, é o ideal nesse sistema de valores em que os domésticos constituem o contramodelo, e o "burguês" - em sua acepção primitiva de patrão, empregador, alguém estabelecido por conta própria -, o ideal. Entre os dois pólos simbólicos "patrão/doméstico", articula-se todo um vocabulário de distinção que isola os domésticos dos outros trabalhadores: "salário" e "remuneração", "uniforme" e "libré", "funcionários" e "empregados".

\section{A Nação rejeita seus domésticos}

No final do século XVIII, as representações sociais dos domésticos já eram bastante elaboradas. ${ }^{4} \mathrm{O}$ criado e seu amo são personagens clássicas do teatro, e as questões de liberdade (quem é mais livre) e de obediência (quem dá as ordens) estão no centro dessas representações. Enganar, disfarçar-se e assumir uma falsa identidade são traços fundamentais na representação dos domésticos. A famosa caricatura de Louis-Sébastien Mercier no Tableau de Paris (publicado em 1782-1788) expõe uma outra faceta dessas representações sociais: o ócio e a esterilidade social e econômica. ${ }^{5}$

Alguns sugerem que se tirem conclusões disso, e em Toulouse, no final do século XVIII, propõe-se obrigar os domésticos a usar um sinal distintivo que permita reconhecê-los. ${ }^{6}$ Daí a excluí-los do corpo nacional falta apenas um passo.

No Essai sur la constitution et les fonctions des assemblées provinciales (Ensaio sobre a Constituição e as Funções das Assembléias Provinciais, 1788), Condorcet enumera todos aqueles que estão excluídos do direito de cidade, e entre eles os domésticos. ${ }^{7}$ Segundo Sieyès, os domésticos são "aqueles que uma dependência servil mantém ligados, 
Um fio de diferença: masculinidades no mundo do trabalho, 1870-1910

não a um trabalho qualquer, mas às vontades arbitrárias de um patrão". 7 As pessoas dependentes não podem, a priori, ter uma opinião diferente da de seu patrão. Em 1789, as mulheres, as crianças e os domésticos são afastados do sufrágio, uma medida que, na época, parecia "natural".

Fazendo parte do domus e da familia, os domésticos se encontram, no século XIX, entre a servidão e o assalariamento, e não é por acaso que são chamados "empregados da casa". Segundo o direito do Antigo Regime, o doméstico pertence à família de seu patrão; nesta posição, não pode se casar sem seu aval e menos ainda deixálo conforme sua vontade.

Em 27 de outubro, a Constituinte, decretando um quinto critério de elegibilidade, torna ainda mais precisa a noção de domesticidade: "não estar em um estado de domesticidade, isto é, de criado da casa". ${ }^{10}$ Mais tarde, os termos do debate se cristalizam entre a Constituição do Ano III (1795) e a do Ano VIII (1799). O artigo 18 da Constituição de 1793 enuncia que "todo homem pode oferecer seus serviços e seu tempo; mas não pode se vender, nem ser vendido; sua pessoa não é uma propriedade alienável. A lei não reconhece a domesticidade; somente pode haver um comprometimento de responsabilidades e de reconhecimento entre o homem que trabalha e o que o emprega". Resumindo, cidadania e pertencimento à Nação não condizem com o estado de domesticidade. Será necessário esperar até 1848 para ver os domésticos homens terem sua cidadania plenamente admitida e exercerem o direito de voto.

Todos esses elementos povoam o imaginário social ao longo de todo o século XIX. No contexto de um mundo do trabalho caracterizado por fronteiras imprecisas e por uma forte interpenetração entre grupos sócio-profissionais, essas imagens deslizam de um campo a outro e "contaminam" setores vizinhos, simbolicamente próximos da domesticidade. 


\section{Os "empregados da casa"}

Em 1894, o Journal des Gens de Maison, o órgão da câmara sindical do setor, mostra-se particularmente sensível ao fato de que, apesar de seu número, os empregados domésticos não conseguem ser considerados plenamente participantes do mundo operário. Por ocasião do debate a respeito de um imposto sobre os domésticos, o jornal indigna-se: "como os socialistas aceitariam que o governo imolasse toda uma categoria de trabalhadores - a mais numerosa deste país - no altar de suas reivindicações? E isso sob o pretexto falacioso de que os domésticos constituem uma categoria refratária às suas doutrinas? [...] em quê os domésticos diferem dos outros trabalhadores? [...] afinal, os domésticos não pagam o imposto de sangue?". ${ }^{11}$ Percebe-se bem o que está em jogo: os domésticos se sentem rejeitados pela nação e pela classe ao mesmo tempo. Essa categoria de trabalhadores fica de fora do movimento operário, mesmo com esforços para se organizar e uma vontade expressa de reconhecimento por parte dos "verdadeiros operários".

O crescimento do número dos domésticos e as transformações na sociedade francesa modificam essas tendências. A expansão e o enriquecimento de uma classe média em vias de aburguesamento durante a segunda metade do século XIX são acompanhados por um desenvolvimento da domesticidade que reúne criados, babás, cocheiros, domésticas ou cozinheiras. O número de domésticos, de ambos os sexos, cresce em números absolutos até 1890; depois se estabiliza, entre 1896 e 1911, em um efetivo em torno de 900.000 a 1.000.000. ${ }^{12}$ Esse crescimento é acompanhado por uma forte feminização: em 1851, os homens representavam 31\% do efetivo; em 1901, não são mais que $17 \% .^{13}$ Os homens, mais facilmente que as mulheres, encontram melhores caminhos. ${ }^{14}$ Entre os domésticos, no entanto, esse fenômeno é sentido como um problema, e 
Um fio de diferença: masculinidades no mundo do trabalho, 1870-1910

o Journal des Gens de Maison constata que "[...] os domésticos sofrem uma terrível crise há alguns anos: aos poucos, tende-se a eliminálos, a substituí-los por mulheres". ${ }^{15}$ A feminização da profissão provoca fortes tensões, e o afastamento dos domésticos se traduz cada vez mais pelo questionamento de sua virilidade. Quando o jornal La France faz uma alegação pouco sutil que constata que "a primeira e a melhor das referências para um doméstico é, então, não ter filhos...", ${ }^{16}$ o Journal des Gens de Maison indigna-se com o fato de que os domésticos sejam acusados do declínio demográfico da França, expondo assim a crescente sensibilidade do setor. As estatísticas pouco numerosas de que dispomos indicam, de fato, uma idade média de casamento relativamente elevada para os domésticos, mais ainda para os homens do que para as mulheres, e um índice de celibato bastante alto. ${ }^{17}$ No contexto mais amplo de uma angústia demográfica, ${ }^{18}$ a dupla exclusão dos domésticos, da Nação e da classe operária, adquire uma nova dimensão, e os qualificativos tornam-se cada vez mais sexuados: esterilidade, dependência, submissão. As angústias da sociedade francesa se projetam sobre os empregados domésticos. O Journal des Gens de Maison continua ecoando esse imaginário social: "[...] o empregado, de qualquer sexo, é quase uma coisa, um instrumento; [...] impõe-se-lhe uma postura e uma linguagem estabelecidas a partir de um protocolo; se homem, recusa-selhe o direito de usar bigodes [...]". ${ }^{19}$ Submisso e estéril, o doméstico é também glabro, um sinal corporal de seu estado de dominado, uma marca que associa o inferior ao emasculado. As dúvidas em relação à virilidade de domésticos tornam-se uma parte de sua representação, moldando-a.

Quando a nova ciência da medicina legal cria um novo quadro para compreender a homossexualidade masculina com uma tipologia que enfatiza o vestuário, a aparência, os gostos e os aspectos físicos ${ }^{20} \operatorname{como}$ indícios da "perversão dos pederastas", os domésticos encontram-se no centro dessa nova classificação. ${ }^{21}$ Os médicos legistas são incitados durante o exame de um suspeito a "ater-se principalmente aos 
caracteres sexuais secundários", como a pilosidade ${ }^{22}$. Essas representações circulam nos meios mais diversos, como atesta a seguinte anedota: um relatório da polícia parisiense de 16 de maio de $1905^{23}$ evoca "o bar situado no quai de l'Hôtel de Ville, número 16 [...] freqüentado em grande parte por compatriotas do dito Févry, que o seguiram em seu novo estabelecimento; estes, em parte domésticos (criados, cocheiros, etc.), têm, devido à sua profissão, o rosto barbeado, o que fez com que os vizinhos supusessem estar diante de pessoas de costumes indecorosos". Os vizinhos, inquietos com a freqüentação glabra desse estabelecimento, denunciam à polícia aquilo que eles pensam ser um ponto de encontro dos homossexuais. Os ramos de serviço, tendo à frente a domesticidade, encontram-se, no fim do século XIX, sob uma crescente pressão simbólica.

\section{Os garçons de receitas do Banco da França}

Alguns conflitos sociais encetados durante as primeiras décadas da Terceira República em torno do direito de usar bigodes permitem pôr à prova nossas hipóteses relativas às representações presentes no mundo do trabalho. Nessa ótica, o caso dos garçons de receitas do Banco da França é particularmente interessante, já que tange a um setor do mundo do trabalho que parece gozar de um certo prestígio.

Os garçons de receitas ocupam os baixos escalões da hierarquia do Banco da França. Seu papel é, então, o de apresentar aos signatários os documentos de cobrança e de receber o equivalente em espécie. Após esse serviço matinal, eles atendem o público nas dependências do Banco. Esses agentes de uniforme cinza e chapéu bicorne são personagens familiares da paisagem urbana parisiense. No final do Segundo Império, Maxime Du Camp os descreve nestes termos: "[...] os garçons de receitas do Banco da 
Um fio de diferença: masculinidades no mundo do trabalho, 1870-1910

França são bem conhecidos em Paris. Quem nunca os viu passar [...] quem nunca se impressionou com essas figuras bem-encaradas sem bigodes, com seu andar ligeiro, com o ar de probidade que parece atenuar os traços de seus rostos??. ${ }^{24}$ Esse rápido retrato já introduz o problema do bigode, mostrando sua ausência. Quanto ao fato de essa ausência ser um problema real, os eventos dos dois anos seguintes (1870 e 1871) praticamente não deixam dúvidas: glabros no final dos anos 1860, os garçons de receitas passam a usar bigodes até setembro de 1871, quando o jornal L'Ordre anuncia que o diretor do Banco da França acaba de proibi-los de usar barba e bigodes, tolerados desde o cerco de Paris. ${ }^{25}$ Entre a época em que Maxime Du Camp publica seu croqui e o artigo do jornal L'Ordre, os garçons de receitas mudaram de figura. É o mesmo Maxime Du Camp que retoma a pena para descrever as aventuras dos funcionários do Banco durante a guerra franco-prussiana e a Comuna de Paris. Esses funcionários, que "trocaram a pena pelo fuzil", ${ }^{26}$ se militarizaram, conforme a expressão utilizada por Du Camp. ${ }^{27}$ Como assinala o jornal L'Ordre, essa militarização é acompanhada pela adoção do atributo militar/viril por excelência, o bigode. Esses homens de "figuras bem-encaradas sem bigodes", descritos por Du Camp, se livraram, através da experiência militar, de uma situação que consideravam desagradável. Para eles, a militarização deu direito à virilidade. No Banco, esses atributos usados pelos garçons de receitas são desconsiderados. Por enquanto, a ordem não é seguida, mas nem por isso o problema desaparece, e em alguns anos as tensões descambam para um conflito aberto. Finalmente, em 1878 a direção volta à carga. Durante mais de um mês, os jornais acompanham o caso, expondo os elementos de um imaginário social subjacente. O primeiro elemento é o recrutamento militar desses agentes. $\mathrm{O}$ bigode assinala que seu portador é um guerreiro e um homem digno desse nome - tanto para os garçons de receitas quanto para os empregados domésticos. O que nos leva ao segundo elemento. De acordo com La Lanterne, jornal 
republicano e anticlerical, privar os gargons de receitas de seu atributo militar/viril seria dar-lhes "o aspecto de uma tropa de lacaios aos quais as duquesas e os novos ricos impõem o uso diário da lâmina de barbear sobre o lábio superior. [...] Nem todos se sentem dignos de erguer a cabeça com rosto glabro, com menos pêlos do que na mão. Hoje, que todo francês se orgulha de ser soldado e de mostrar isso, cada um busca ter a liberdade de se barbear como lhe parecer melhor, e nós compreendemos que os funcionários do Banco ranjam os dentes sempre que os comparamos a homens que têm a infelicidade de não serem livres, como os lacaios de casas de família ou os garçons de café". ${ }^{28}$ Ser francês e livre é ser soldado, ter o atributo correspondente e, sobretudo, distinguirse dos domésticos. $\mathrm{O}$ militar bigodudo encarna a virilidade ideal, e o lacaio é a antípoda: intrinsecamente afeminado e, portanto, glabro. $\mathrm{O}$ primeiro representa o homem livre; o segundo, o escravo. Essa virilidade militar e seu atributo são a única maneira de ser e de parecer um homem livre, e torna-se assim o "bilhete de entrada" para a Nação e para a classe operária.

O Petit Journal de 15 de setembro é ainda mais explícito sobre esse ponto: "entre os empregados das casas burguesas, dos restaurantes, dos cafés, a proibição do bigode é um sinal de dependência. Brava gente, classe interessante da sociedade, sem dúvida; mas por que comparar esses bancários a domésticos?". Proibir o bigode é impedi-los de manifestar sua independência e reivindicar sua virilidade. Também é questioná-las.

Os garcons de receitas aceitam totalmente as regras do jogo, apenas contestam sua desqualificação, conforme expresso em uma petição que submeteram ao governador. Nesse texto, eles apresentam dois argumentos. O primeiro (e principal) é militar: "a maioria desses agentes sai das fileiras do exército, e vários deles são cavaleiros da Legião de Honra ou condecorados militares. A administração do Banco pôde estimar sua coragem e seu devotamento durante os dois cercos de Paris". O batismo de fogo transforma o homem a ponto de ele não ser mais um simples "paisano". Esses antigos militares conquistaram, através de seu sangue, 
Um fio de diferença: masculinidades no mundo do trabalho, 1870-1910

uma respeitabilidade e o direito de usar os atributos que a atestam. Mas essa solicitação foi recusada, e é preciso esperar até 1882 para que a proibição seja retirada.

Por que essa proibição? La Lanterne propõe uma explicação invocando a trajetória do governador Roland. Segundo esse jornal, o regulamento que o governador acabava de resgatar e de recolocar em vigor datava da Restauração, época em que o bigode significava uma oposição ao regime e um apego ao Império e aos valores republicanos. Roland revive 1815 em 1878. Essa interpretação político-cultural, ainda que possível, não é a única dimensão do problema. É preciso também levar em conta as sensibilidades de alguns grupos que se mostraram bastante preocupados com a mise-enscène das relações sociais.

O jornal Le Figaro de 11 de julho de 1872 oferece um indício importante ao denunciar o que qualifica de "inconveniência por parte dos garçons do Banco da França". Seu erro seria recusarem-se a subir pela escada de serviço, reservada aos fornecedores, e preferirem deixar uma notificação com os zeladores. ${ }^{29}$ As mesmas queixas se repetem nos jornais parisienses dos anos 1870, por vezes em cartas de leitores. Esses pequenos conflitos revelam o que realmente está em jogo. Quem são esses funcionários? Como são percebidos por seus clientes? Trata-se realmente de clientes? A denominação de garçons já revela muito: os agentes ambulantes do Banco da França são percebidos pelos devedores como empregados domésticos. Eles são esperados nas casas e devem subir pela escada de serviço. Não negociam com "clientes", mas com patrões, e não são funcionários, mas domésticos.

À pressão externa se soma uma pressão interna. No início de 1879, o jornal L'Événement evoca o problema dentro do próprio Banco: “recebemos de um funcionário 'subalterno' do Banco da França uma carta nos solicitando fazer a defesa da causa desses bravos agentes aos quais o uso de bigodes continua proibido [...] e você sabe por que o Governador permite aos escriturários usarem 
barba à vontade, enquanto o proíbe aos garcons de receitas? Simplesmente porque os primeiros são 'funcionários' (employés) [...] o que são então os garçons de receitas? O Governador ficaria bem embaraçado para explicar!" 30 As aspas acrescentadas pelo jornal à palavra "funcionários" remetem ao problema do status real dos garçons de receitas no Banco da França. Uma linha tênue separa os agentes ambulantes do Banco dos "escriturários", que ocupam os escalões mais altos da hierarquia e não precisam fazer visitas a domićlio. Então, o conflito em torno do direito de usar bigodes é também uma luta relativa à visibilidade dessa linha ou, em outras palavras, uma luta entre garçons e "funcionários de colarinho branco". O uso de bigodes é um elemento importante em uma estratégia de integração dos garçons de receitas entre os funcionários do Banco.

Entre os funcionários internos que querem se distinguir deles e uma clientela que procura afirmar seu status social, os garcons de receitas se vêem forçados ao papel de lacaios. Esse status de domésticos atesta a supremacia social de seus colegas, ao mesmo tempo em que conforta e reafirma a posição social de alguns clientes do Banco. Dominação e submissão, feminilidade e virilidade, glória das armas e do uniforme: o bigode é o epicentro de um imaginário denso, ao qual o peso simbólico dos eventos do "ano terrível" acaba de acrescentar novas camadas de sentido. Sua ausência, e mais ainda sua proibição, são consideradas como uma ferida e um ato de exclusão e de emasculação. Enquanto tal, o uso de bigodes permitiu a esses funcionários subalternos do Banco da França cobrir seu déficit simbólico e impor-se a outros grupos sociais.

\section{Os garçons de café}

Mais numerosos e visíveis que os garçons de receitas do Banco da França, os garçons de cafés e de restaurantes sentem na pele a nova cultura das aparências. 
Um fio de diferença: masculinidades no mundo do trabalho, 1870-1910

Os grandes restaurantes e cafés parisienses foram se configurando durante a Restauração e a Monarquia de Julho (1830), até encontrar estruturas quase definitivas por volta da metade do século XIX. O Segundo Império é, sem dúvida, a época da consolidação dos grandes estabelecimentos parisienses durante as Exposições Internacionais ${ }^{31}$.

É a época em que o restaurante moderno é, de certa forma, "inventado" simultaneamente como instituição e como representação social. ${ }^{32} \mathrm{O}$ próprio nascimento desses estabelecimentos é marcado por um fenômeno que um comentarista do início do Segundo Império qualificou como "ordem de coisas aristocráticodemocrática". ${ }^{33}$ No início do século XIX, a vontade de imitar a nobreza (ou, mais precisamente, as representações desta) encontra as circunstâncias que permitem, quase favorecem, a transformação da glutonaria em mercadoria, dotada de grande visibilidade e crescente acessibilidade, apoiada em novos modos de "midiatização", sobretudo através da imprensa. Novos grupos sociais cobiçam tudo o que cheira a aristocracia, transformando isso em produtos de consumo. ${ }^{34}$ Para aqueles que não freqüentam os salões, os bulevares e seus "lugares da moda", os cafés e os restaurantes constituem uma escola permanente de tudo o que é comme il faut..$^{35}$

$\mathrm{O}$ escritor Eugène Briffault constata que "[...] comer bem era o privilégio da opulência; os restaurantes colocaram isso ao alcance de todo mundo. O homem que pode, uma vez na vida, gastar vinte ou vinte e cinco francos em seu jantar [...] é mais bem tratado do que se jantasse na casa de um príncipe: é servido com tanto esplendor quanto num palácio; pede conforme sua vontade; seu gosto e seu desejo não encontram obstáculos; sem nenhuma consideração, ele somente obedece aos caprichos de suas vontades e de sua gulodice." ${ }^{36}$ Se uma das características da burguesia é a vontade de imitar, pelo comportamento e pelo consumo, uma "aristocracia" imaginada, eis então seu templo. Não se paga apenas pelas comidas e pelas bebidas, mas também e principalmente por

Anos 90, Porto Alegre, v. 14, n. 25, p.17-35, jul. 2007 
uma afirmação de sua identidade e de seus pertencimentos. Por um momento, ele é um grande senhor, um príncipe cujos mínimos caprichos são adivinhados e satisfeitos. Nesse contexto, o serviço desempenha um papel-chave, e os garçons fazem parte do produto cultural oferecido aos consumidores.

No decorrer do século, o pessoal desses estabelecimentos sofreu transformações até o momento da codificação do café e do restaurante parisienses, provavelmente no final do Segundo Império. ${ }^{37}$ Assim como os empregados domésticos, os garçons não encontram lugar no mundo operário e, de forma geral, na sociedade. Essa posição indeterminada é fortemente marcada no imaginário social.

\section{Rumo a um conflito aberto}

Pelo fim do século XIX, as tensões aumentam nos cafés parisienses. Em 1891, os garçons encaminham à câmara sindical uma petição com 760 assinaturas: "voluntária e assiduamente submetidos a todas as exigências reais e justificadas de nossa profissão, suportamos com pesar uma servidão cujo motivo não vislumbramos; estamos convencidos de que esse grande público parisiense, tão esclarecido, tão liberal, tão humano, receberia com o bom humor habitual uma humilde reforma que nos é tão importante, e que veria sem desgosto seus zelosos servidores usarem nas salas públicas os bigodes que usam na caserna". ${ }^{38}$ Esse texto revela ao mesmo tempo os traços do imaginário social e a realidade estruturada por esse imaginário. A ausência do bigode é reconhecida por aqueles a quem tal restrição é imposta como um atributo de escravidão. $\mathrm{O}$ argumento dos patrões é de que se trata de uma marca de reverência exigida pelos clientes, e o serviço militar é vivenciado como um rito de passagem e um direito de entrada no país da liberdade, da igualdade e da virilidade. 
Um fio de diferença: masculinidades no mundo do trabalho, 1870-1910

Um projeto de lei proposto em dezembro de 1906 mostra a que ponto o bigode era uma peça importante na construção de identidades do mundo do trabalho. Antide Boyer, pitoresco deputado de Bouches-du-Rhône e membro do grupo socialista, propõe uma legislação segundo a qual o uso de bigodes concerniria à vida privada, ou seja, a uma escolha pessoal, a um direito inalienável do homem. Seu discurso introdutório é um resumo dos argumentos propostos meio século antes, principalmente pelos advogados envolvidos no conflito relativo ao direito de usar bigodes nos tribunais. O discurso de Boyer se detém longamente sobre a domesticidade e as ocupações que a ela são simbolicamente associadas: "[...] nas ditas casas de família, nobres e burgueses ainda acreditam distinguirse proibindo a seus empregados - que tratam como escravos - o uso de bigodes na sua frente. Os donos de restaurantes e de cafés, imitando esse exemplo, imaginam provar sua superioridade sobre alguns concorrentes exigindo de seus empregados que não usem bigodes. As pessoas pretensamente distintas, segundo alguns donos de estabelecimentos, prefeririam consumir mal a se verem desrespeitadas pela autorização do uso de bigodes pelos garçons" ${ }^{\prime 3}$.

O deputado associa empregados domésticos a garçons de cafés e restaurantes: nesses estabelecimentos, os clientes podem ao mesmo tempo consumir e se sentir grandes senhores. Os empregados dos cafés e dos restaurantes, enquanto servem o público, desempenham um papel em uma peça de teatro ${ }^{40}$ na qual o consumidor é o "Senhor" e o garçom é o criado. As representações sociais, desempenhadas dessa forma, ultrapassam amplamente o domínio das relações empregador/ empregado para se tornarem literalmente um jogo social: aqueles que pagam compram mais, muito mais do que seu consumo; eles confirmam sua posição e reafirmam sua superioridade. Eles são patrões e, por não terem empregados domésticos em casa, alugam alguns por um curto instante num café parisiense da moda.

Seis meses mais tarde, as tensões acumuladas durante algumas décadas se traduziram por um conflito aberto, no âmbito de uma 
greve de vários ofícios do ramo da alimentação desencadeada em 11 de abril de 1907. Os primeiros a entrar em greve foram os padeiros. Alguns dias depois, os garçons de café e os garçons de bares se juntam a eles. "O que eles querem? Pergunta um velho senhor muito decente. O direito de não trabalhar como bestas de carga, de não mais pagar o patrão antes de trabalhar e de usar bigodes como vocês usam barba", replica o jornalista do L'Humanité. ${ }^{41}$ Em 19 de abril, a greve dos garçons de bares ${ }^{42}$ se estende, e o direito de usar bigodes se mostra claramente como uma reivindicação importante dos empregados do setor.

Patrões interrogados pelo jornal declaram: "se a autorização para o uso de barba for generalizada, a partir de então deixaremos nossas funções para sermos garçons de café; na verdade, esses ganham em torno de cem francos a mais do que nós e não são menos considerados pelo cliente". ${ }^{43}$ Mesmo abstraindo os exageros, notemos que o direito à barba é considerado como a última vantagem dos patrões.

Em 4 de maio, os garçons de bares e de restaurantes encerram a greve. Fazendo o balanço, L'Humanité declara: "os garçons de café e de restaurante terão também o direito de usar bigodes; eles não serão mais assimilados a párias que somente poderiam ganhar seu pão com a condição de ter no rosto o estigma de servidão que só é imposto aos empregados domésticos" "42. Essas tensões se manifestam ao longo de todo o conflito. No "Café de la Paix", os grevistas declaram: "queremos nosso lugar de homens como todos os trabalhadores, e não sermos submetidos a imitar as mulheres suprimindo os bigodes". 45

Essas mesmas tensões reais e simbólicas serão expressas, alguns anos mais tarde, na obra de Marcel Proust. Sensível principalmente aos efeitos semânticos desses fenômenos que revolucionavam a sociedade de seu tempo, Proust se serve do ascensorista do Grande Hotel de Balbec como "informante" para uma exposição de arqueologia lingüística. 
Um fio de diferença: masculinidades no mundo do trabalho, 1870-1910

Ele “...pertencia a esse proletariado moderno que pretende apagar da linguagem qualquer vestígio do regime da domesticidade. Mas em seguida me anunciou que na 'colocação' em que ia 'continuar' teria uma 'túnica' mais bonita e 'honorários' melhores; e é que as palavras 'uniforme' e 'salário’ lhe pareciam antiquadas e inconvenientes. E como, por um caso de absurda contradição, o vocabulário sobreviveu, apesar de tudo, no espírito dos 'patrões', à concepção da desigualdade, acontecia que eu sempre interpretava mal o que me dizia o ascensorista. $\mathrm{O}$ que eu queria saber era se minha avó se achava no hotel. E antes que eu lhe perguntasse qualquer coisa, dizia-me ele: 'essa senhora acaba de sair de seu quarto'. Eu jamais atinava com a coisa e imaginava tratar-se de minha avó. 'Não, essa senhora que é, penso eu, empregada dos senhores'. Como na antiga linguagem burguesa, que pelo visto já devia estar abolida, não se considerava a cozinheira como empregada, eu ficava um momento a pensar: 'Enganou-se, pois nós não temos fábrica nem empregados'. Logo me vinha à mente que o nome de empregado é o mesmo que o uso de bigode para os garçons: uma satisfação de amor-próprio que se dá aos criados, e que essa senhora que acabava de sair era Francisca [...]; tal satisfação ainda não parecia bastante ao rapaz do elevador, porque costumava dizer da gente de sua classe e idade, em tom de compaixão: 'o trabalhador', ou 'o pequeno', empregando o mesmo singular coletivo de Racine quando diz: 'o pobre...”. 46

Essa passagem bastante densa é um tecido bordado sutilmente com fios colhidos de diversas representações. O Grande Hotel de Balbec é a catedral desse culto cujas igrejas paroquiais são os grandes cafés parisienses. $\mathrm{O}$ ascensorista desempenha aqui um papel semelhante ao dos garçons no Riche, no Américain, no Cardinal ou no Wepler.

O ascensorista, colocando-se intuitivamente no mesmo nível da cozinheira, utiliza em relação a ela a mesma linguagem que aplica a si próprio. Elevando Francisca à dignidade de empregada, ele dá a si mesmo essa distinção; de onde o mal-entendido, o diálogo de

Anos 90, Porto Alegre, v. 14, n. 25, p.17-35, jul. 2007 
surdos entre dois mundos e duas línguas. Paralelamente às lutas sociais politizadas como as greves, outras áreas se transformam em campos de batalha, menos conscientes, mas também apaixonadas e obstinadas. A fábrica cristaliza o pólo avançado do mundo profissional. A atenção se volta para ela, e as imagens edificantes do socialismo se fixam ao seu redor. $\mathrm{Na}$ fábrica, os trabalhadores são empregados, um termo que, no século XIX e no início do XX, tem o sentido do atual "funcionário". O empregado é digno de respeito; o que ele ganha são honorários.

Todas essas "cenas", interpretadas milhares de vezes por dia nos cafés, nos salões, nos grandes hotéis e passeios da moda, constroem "a burguesia". Nessas "cenas", o papel daquele que serve - como a camareira do teatro - é essencial, pois a dominação e a independência constituem os elementos-chave do modelo masculino hegemônico. Os empregados domésticos - dominados e dependentes - são os "afeminados" por excelência do mundo do trabalho. Ao preço de sua própria virilidade, o servidor (servant) e de modo mais geral o trabalhador que atua no ramo de serviços - afirmou o pertencimento de seu cliente/patrão a esse modelo. O modelo militar é um meio disponível e eficaz de restabelecer uma relação mais equilibrada, e de "salvar a honra". Ora, pelo mesmo motivo, a adesão à "classe de verdadeiros homens" - e, portanto, bigodudos - é fundada sobre a exclusão, real e simbólica, daqueles que não o são. Os bigodes dos garçons do Banco da França e aqueles dos garçons de café realmente romperam com a aparência da hierarquia, mas apenas para substituí-la por uma aparência de igualdade. 
Um fio de diferença: masculinidades no mundo do trabalho, 1870-1910

\section{Notas}

${ }^{1}$ Charles Christophe. Histoire sociale de La France au XIXe siècle. Editions du Seuil, 1991, p. 316.

${ }^{2}$ Em francês, garçons de recettes. Funcionário bancário do baixo escalão encarregado de fazer as cobranças bancárias externas, em visitas a domicílio. Optou-se por manter a palavra garçons, que significa literalmente meninos, porque esse termo tem uma incidência na construção da representação social desses indivíduos. Também remete aos atendentes de restaurantes e bares, como no português "garçom". (N. do T.) ${ }^{3}$ A partir da Revolução Francesa e do fim do Antigo Regime, a divisão política da França compreende cinco períodos republicanos. A Terceira República vai de 1875 a 1940, mas geralmente abrange os cinco anos precedentes, considerados a "primeira” Terceira República, período em que ocorreram a guerra franco-prussiana (187071), a Comuna de Paris (1871) e o cerco de Paris (1870). Daí o ano de 1870 ser considerado o "ano terrível". ( $\mathrm{N}$ do T.)

${ }^{4}$ AMMIRATI, Charles. Les rapports entre maîtres et valets dans la comédie du XVIII ${ }^{e}$ siècle: thèmes et sujets. Paris, Presses universitaires de France, 1999.

BLANC, André; FREUNDLICH, Francis; PERCHELLET, Jean-Pierre et al. Étude sur maîtres et valets dans la comédie française du XVIII siècle, Paris; Ellipses, 1999.

DIDIER, Béatrice; PONNEAU, Gwenhaël (dir.), Le maître et le valet: figures et ruses du pouvoir, Paris; SEDES, 1998.

SABATTIER, Jacqueline, Figaro et son maître: maittres et domestiques à Paris au XVIII ${ }^{\mathrm{e}}$ siècle; Paris: Perrin, 1984.

MAZA, Sarah C., Servants and masters in eighteenth-century France: the uses of loyalty. Princeton, N. J., Guildford, G. B.: Princeton University Press, 1983.

MORAUD, Yves; La Conquête de la liberté de Scapin à Figaro: valets, servantes et soubrettes de Molière à Beaumarchais. Paris: Presses Universitaires de France, 1981.

${ }^{5}$ MERCIER, Louis-Sébastien, Le Tableau de Paris: Librairie François Maspero, Paris: 1979, p. 160-162.

${ }^{6}$ BERTHÉLÉ, Joseph: Montpelier em 1768 et 1836 d'après deux manuscrits inédits. Montpelier: Serre et Roumégous, 1909, p. 69.

${ }^{7}$ Oeuvres de Condorcet, t. VIII, p. 130.

${ }^{8}$ SIEYÈS E. Considérations sur le rapport du comité de Constitution, p.22, citado por Pierre Rosanvallon, Le sacre du citoyen, Gallimard, 1992, p. 155.

${ }^{9}$ Rosanvallon, op. cit., p. 143. CASTAN, Yves, Honnêteté et relations sociales en Languedoc, 1715-1780, p. 181.

${ }^{10}$ Rosanvallon, op. cit., p. 156.

${ }^{11}$ JGM, 8 de maio de 1894.

${ }^{12}$ MARTIN-FUGIER, Anne. La domesticité féminine à Paris en 1900. Perrin, 2004, p. 35.

Anos 90, Porto Alegre, v. 14, n. 25, p.17-35, jul. 2007 


\section{Gil Mihaely}

${ }^{13}$ MCBRIDE, Theresa, The Domestic Revolution: The Modernisation of Household Service in England and France, 1820-1920. London: Croom Helm, 1976, p. 35.

CUSENIER, Marcel, Les domestiques en France. Paris, 1912, cap. 1.

${ }^{14}$ CHARLES, Christophe, Histoire sociale de La France an XIX e siècle. Editions du Seuil, 1991, p. 316-317.

${ }^{15}$ JGM, 8 de junho de 1895.

${ }^{16}$ JGM, 8 de abril de 1892 (cita La France, 7 de fevereiro de 1892).

${ }^{17}$ MCBRIDE, Theresa. The Domestic Revolution: The Modernisation of Household Service in England and France, 1820-1920. London: Croom Helm, 1976, p. 87-89. ${ }^{18}$ ELY, Marie-Gabrielle; GOGLIN, Jean-Marc, "Les campagnes françaises à la fin du XIX $^{\mathrm{e}}$ siècle à travers l'exemple du département de l'Orne et du Canton de Messei", 2002, disponível em: http://www.19e.org/index.htm.

${ }^{19}$ JGM, 8 de julho de 1898.

${ }^{20}$ TARDIEU, Ambroise. Etude médico-légale sur les attentats aux moeurs. Paris: J.-B. Baillière et fils; Londres: H. Baillière ; New York: H. Baillière, 1859 .

${ }^{21}$ TARDIEU, Ambroise. Etude médico-légale sur les attentats aux moeurs, p. 132.

${ }^{22}$ CHEVALIER, Julien. Une maladie de la personnalité: l'inversion sexuelle; Psychophysiologie; Sociologie; Tératologie, Lyon, A. Stork, Paris, G. Masson, 1893, p. 465.

${ }^{23}$ Archives de la Préfecture de Police de Paris (APP), série BM2 no 15, 16, maio de 1905, citado por Régis Revenin, Homossexualité et prostitution masculines à Paris 18701918, L'Harmattan, 2005, p. 31 (nota 117).

${ }^{24}$ CAMP, Maxime du. Paris, ses organes, ses fonctions et sa vie dans la seconde moitié $d u$ XIX ${ }^{e}$ siècle. Hachette, 1870, 6 vol., vol. 2, p. 415-416.

${ }^{25}$ L'Ordre, 11 de setembro de 1871.

${ }^{26}$ Poema do empregado Bramtot, citado por Eric Cavaterra, La Banque de France et la Commune de Paris 1871, Edition L'Harmattan, 1998.

${ }^{27}$ Ibid.

${ }^{28}$ La Lanterne, 16 de julho de 1878.

${ }^{29}$ Le Figaro, 11 de julho de 1872.

${ }^{30}$ L'Evénement, 27 de fevereiro de 1879.

${ }^{31}$ BROWN, Frederick. Theatre and Revolution: The culture of the French Stage. New York: Viking Press, 1980, p. 8-9.

${ }^{32}$ SPANG, Rebecca L. The invention of the restaurant: Paris and modern gastronomic culture, Cambridge (Mass.): Harvard University Press, 2000.

${ }^{33}$ DELORD, Taxile; FRÉMY, Arnould; TEXIER, Edmund. "Paris Restaurant", in idem, Les petits Paris. Paris: A. Taride, 1854, p. 22.

${ }^{34}$ Sobre esse ponto: ARON, Jean-Paul. Le mangeur $d u$ XIX ${ }^{e}$ siècle. Paris: Edition Payot, 1989, pp. 8 e 13-15 para os aspectos contemporâneos da "midiatização" da gastronomia desde seus primeiros passos nos anos 1780 .

Anos 90, Porto Alegre, v. 14, n. 25, p.17-35, jul. 2007 
Um fio de diferença: masculinidades no mundo do trabalho, 1870-1910

${ }^{35}$ Ver: D'ARISTE, Paul. La vie et le monde du boulevard (1830-1870). Paris: Editions Jules Tallandier, 1930, p. 32-33, 40-41.

${ }^{36}$ BRIFFAULT, Eugène. Paris à Table. Genève-Paris: Editions Slatkine, 1980, p. 148-149.

${ }^{37}$ ARON, Jean-Paul. Le Mangeur de XIX' siècle, p. 81.

${ }^{38}$ De Langle, op. cit., p. 99.

${ }^{39}$ Proposta de lei relativa à humilhante proibição de usar bigodes, imposta por alguns patrões a uma grande parte dos trabalhadores... apresentada por M. Antide Boyer, em $1^{\circ}$ de dezembro de 1906. Câmara dos Deputados, 9ª legislatura. Sessão extraordinária de 1906. No 503.

${ }^{40}$ De qualquer forma, a principal fonte de informações sobre as grandes casas era o teatro de rua.

${ }^{41}$ L'Humanité, 17 de abril de 1907.

${ }^{42}$ A imprensa utiliza os termos "garçom de café", "garçom de bar" ou apenas garçom sem distinção.

${ }^{43}$ L'Humanité, 21 de abril de 1907.

${ }^{44}$ L'Humanité, 4 de maio de 1907.

${ }^{45}$ L'Humanité, 20 de abril de 1907.

${ }^{46}$ Tradução utilizada: PROUST, Marcel. Em Busca do Tempo Perdido II, À Sombra das Raparigas em Flor. (escrito entre 1909 e 1921). Porto Alegre: Editora Globo, 1973. Tradução de Mario Quintana.

Recebido em 24/07/2007

autor convidado

Anos 90, Porto Alegre, v. 14, n. 25, p.17-35, jul. 2007 